\title{
Neurotransmitters and Motor Activity: Effects on Functional Recovery after Brain Injury
}

\author{
Larry B. Goldstein \\ Department of Medicine (Neurology), Duke Center for Cerebrovascular Disease, Duke University, Durham, North Carolina; and \\ Durham Department of Veterans Affairs Medical Center, Durham, North Carolina
}

Summary: There are complex relationships among behavioral experience, brain morphology, and functional recovery of an animal before and after brain injury. A large series of experimental studies have shown that exogenous manipulation of central neurotransmitter levels can directly affect plastic changes in the brain and can modulate the effects of experience and training. These complex relationships provide a formidable challenge for studies aimed at understanding neurotransmitter effects on the recovery process. Experiments delineating nore- pinephrine-modulated locomotor recovery after injury to the cerebral cortex illustrate the close relationships among neurotransmitter levels, brain plasticity, and behavioral recovery. Understanding the neurobiological processes underlying recovery, and how they might be manipulated, may lead to novel strategies for improving recovery from stroke-related gait impairment in humans. Key Words: Stroke, motor function, brain injury, norepinephrine, recovery.

\section{INTRODUCTION}

Impaired walking after stroke is associated both with higher levels of disability and with compromised levels of social functioning. Depending on the level of assistance required, this particular deficit can lead to great increases in caregiver burden and so may necessitate the patient's residence in a formal assisted-living environment. Effective strategies aimed at improving poststroke gait impairments would help mitigate its functional and societal consequences.

Much has been learned about the immediate response of the brain to stroke-related injury, as well as its potential for plasticity during the recovery period. Understanding the roles of specific neurotransmitters as modulators of the recovery process could lead to effective poststroke restorative pharmacotherapy.

\section{EFFECT OF EXPERIENCE AND TRAINING ON FUNCTIONAL LOCOMOTOR RECOVERY IN ANIMAL MODELS}

Numerous studies in laboratory animals show that environmental complexity can have a direct impact on an-

Address correspondence and reprint requests to: Larry B. Goldstein, M.D., Director, Duke Center for Cerebrovascular Disease, Box 3651, Duke University Medical Center, Durham, NC 27710. E-mail: golds004@mc.duke.edu. atomical brain plasticity. ${ }^{1}$ Housing in complex environments is associated with overall and regionally specific increases in brain weight, cortical depth, hippocampal thickness, callosal size, and cortical glial density ${ }^{1}$ and has effects on both neuronal morphology ${ }^{1,2}$ and connectivity. ${ }^{3}$ It has also long been recognized that housing animals in complex environments (as opposed to a standard cage), either before or after brain injury, can lead to less severe neurological deficits and more favorable outcomes, ${ }^{4-6}$ although some debate remains as to whether this represents true recovery or enhancement of compensatory behavioral strategies. ${ }^{1}$

In addition to general environmental factors, a large number of laboratory studies also show the importance of training after brain injury for functional motor recovery. ${ }^{2,7,8}$ As summarized in these detailed reviews, exercise can increase levels of neurotrophic factors such as brain-derived neurotrophic factor (BDNF), enhance neurogenesis, and improve learning. Rehabilitative training is associated with specific improvements in motor function after cortex injury in several behavioral paradigms, ${ }^{9-14}$ particularly when this training is coupled with housing in complex environments. ${ }^{12,13}$

Experimental studies in squirrel monkeys suggest that repetitive use of the impaired hand is required for maintenance of the spared portion of the hand representation after motor cortex infarction. ${ }^{15}$ Overuse of the affected limb during vulnerable periods after experimental brain 
injury is, however, associated with both exacerbation of the underlying brain damage, and in some cases, poorer sensorimotor performance. ${ }^{16-22}$ In ischemia models, functional outcome is improved despite exacerbation of injury with exercise begun immediately after the injury. ${ }^{20}$ Delaying training for longer periods can diminish this effect. ${ }^{13}$ Intensive training after the first 3 to 5 days after focal brain injury does not exacerbate lesion size or negatively affect outcome. ${ }^{11,14}$

Based on this extensive literature, it is clear that there are complex relationships among the behavioral experience, brain morphology, and functional recovery of an animal before and after brain injury. These various processes may affect specific neurotransmitter levels, which may in turn affect brain plasticity. Exogenous manipulation of central neurotransmitter levels, however, can directly affect plastic changes in the brain that could modulate the effects of experience and training. These complex interrelationships provide a formidable challenge for studies aimed at understanding neurotransmitter effects on locomotor recovery.

\section{EFFECT OF NOREPINEPHRINE ON NEURAL PLASTICITY}

A large body of work has focused on norepinephrinemodulated locomotor recovery after brain injury, illustrating the close relationships among neurotransmitter levels, brain plasticity, and behavior, For example, norepinephrine has been implicated in trophic changes in the central nervous system. ${ }^{23}$ Local infusion of 6-hydroxydopamine, which depletes central norepinephrine, blocks the effects of monocular light deprivation in kittens. Local infusion of norepinephrine reinstates plasticity in animals that are no longer sensitive to this insult. Increases in both growth-associated protein 43 and synaptophysin immunostaining in the ipsilateral and contralateral cerebral hemispheres, as well as other brain areas, have been associated with amphetamine given after unilateral sensorimotor cortex injury in rats. ${ }^{24}$

\section{Norepinephrine and behavioral recovery}

Pharmacological studies. Numerous experimental studies provide evidence supporting the role of norepinephrine as a modulator of behavioral motor recovery after injury to the motor cortex. Feeney and coworkers ${ }^{25}$ first reported that the administration of a single dose of d-amphetamine the day after a unilateral sensorimotor cortex injury in the rat results in an enduring enhancement of motor recovery. This group later extended the observation to other species and other behavioral deficits. For example, postlesion treatment with amphetamine also enhances motor recovery in cats with unilateral or bilateral frontal cortex ablations ${ }^{26,27}$ and reinstates ste- reoscopic vision in cats with bilateral visual cortex lesions. ${ }^{28,29}$

Although amphetamine may influence the release of a variety of neurotransmitters, several lines of evidence suggest that its effect on recovery is related to enhanced release of central norepinephrine. First, direct intraventricular infusion of norepinephrine (but not dopamine) mimics the effect of amphetamine. ${ }^{30} \mathrm{In}$ addition, pharmacological studies show that the impact on recovery of other adrenergic agonists and antagonists can be predicted based on their effects on the release of norepinephrine from noradrenergic terminals. Both yohimbine and idazoxan (centrally acting $\alpha_{2}$-adrenergic receptor antagonists) increase norepinephrine release and enhance motor recovery when administered to rats as a single dose after unilateral sensorimotor cortex injury. ${ }^{31,32}$ Clonidine, a centrally acting $\alpha_{2}$-adrenergic receptor agonist that decreases norepinephrine release, has a prolonged detrimental effect on motor recovery in rats and reinstates motor deficits when given to animals that had recovered motor function. ${ }^{33,34}$ Prazosin and phenoxybenzamine, centrally acting $\alpha_{1}$-adrenergic receptor antagonists, are also harmful. ${ }^{34-36}$ Coadministration of the butyrophenone haloperidol blocks amphetamine-promoted motor recovery in rats and impairs motor recovery when given alone. ${ }^{25}$ Haloperidol also blocks amphetamine-facilitated visual recovery in visually decorticated cats. ${ }^{29,37}$ Haloperidol, fluanisone, and droperidol each transiently reinstate motor deficits in recovered rats. $^{38}$

Because haloperidol is a dopamine receptor antagonist, these later experiments might be considered as providing evidence for a dopaminergic effect on motor recovery after brain injury; however, haloperidol is also a noradrenergic receptor antagonist. Radioligand binding studies show that haloperidol is a marginally more potent $\alpha_{1}$-adrenergic receptor antagonist than clozapine ( $K_{\mathrm{d}} 6.1$ versus $9 \mathrm{nM}$, respectively), but clozapine is a significantly more potent $\alpha_{2}$-adrenergic receptor antagonist than haloperidol $\left(K_{\mathrm{d}} 160\right.$ versus $3800 \mathrm{nM}$, respectively). As expected, dose-effect experiments found that haloperidol had increasingly detrimental effects on post-brain injury motor recovery with increasing dose. ${ }^{39}$ In contrast, clozapine facilitated recovery at low dose (an $\alpha_{2}$-adrenergic receptor antagonist effect) but impaired recovery at higher doses (an $\alpha_{1}$-adrenergic receptor antagonist effect; FIG. 1). Thus, the dose-related effect of clozapine on recovery (facilitory at low doses and detrimental at higher doses) and the harmful effects of haloperidol are entirely predictable based on a noradrenergically mediated mechanism.

Lesioning studies. Consistent with the pharmacological data, several additional lines of evidence suggest the 


\section{Clozapine}

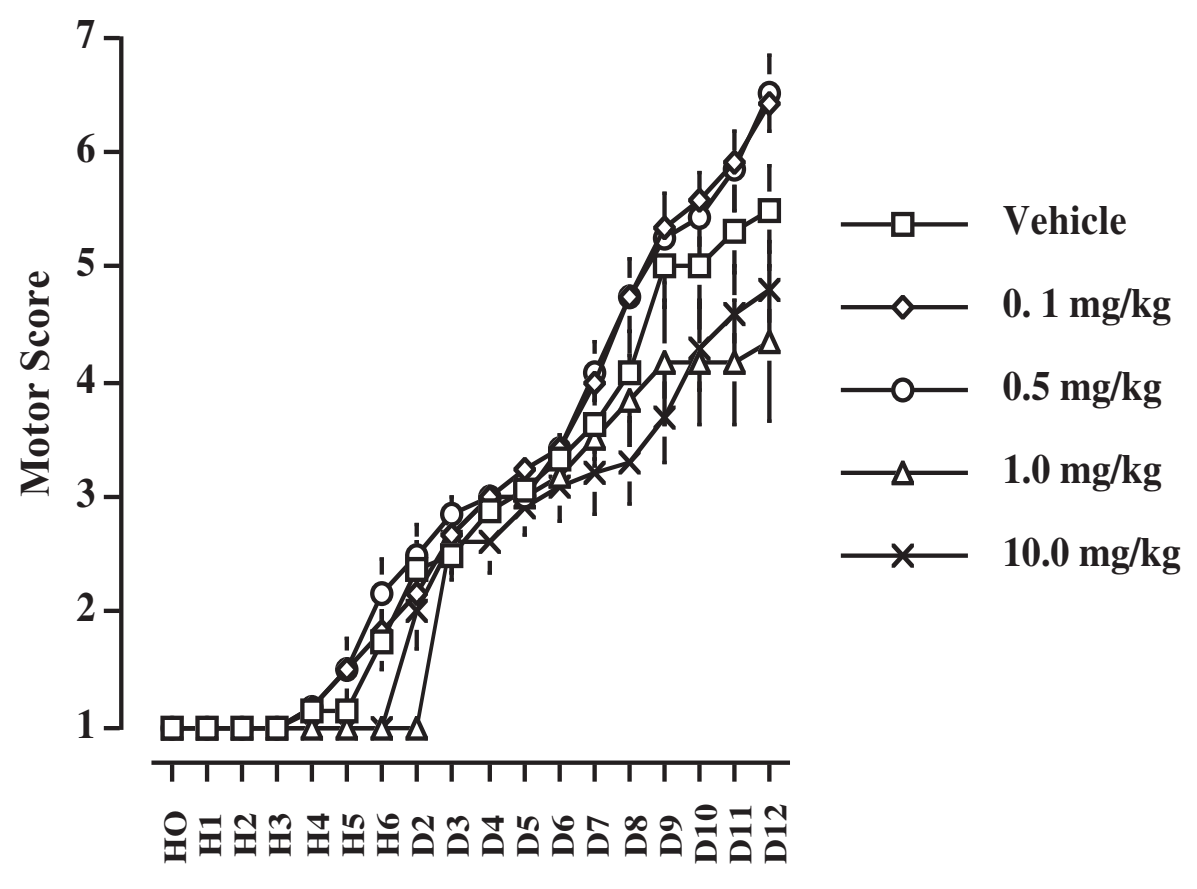

\section{Trial}

FIG. 1. Effect of clozapine at different doses on locomotor recovery after unilateral sensorimotor cortex injury. Trials are identified in hours $(H)$ or days $(D)$ after the first postoperative behavioral testing trial (zero hours, $\mathrm{H} 0$ ) in which the rat is required to traverse a narrow horizontal beam. The baseline first trial, H0, was given 24 hours after cortex lesion surgery. A single dose of vehicle or drug was given immediately after the baseline trial. Symbols represent locomotor scores for each trial (mean \pm SEM). Motor performance was rated on a seven-point scale by an observer blind to the study hypothesis: 1, the rat is unable to place the affected hindpaw on the horizontal surface of the beam; 2 , the rat places the affected hindpaw on the horizontal surface of the beam and maintains balance for at least 5 seconds; 3 , the rat traverses the beam while dragging the affected hindpaw; 4 , the rat traverses the beam and at least once places the affected hindpaw on the horizontal surface of the beam; 5 , the rat crosses the beam and places the affected hindlimb on the horizontal surface of the beam to aid less than half its steps; 6 , the rat uses the affected hindpaw to aid more than half its steps and; 7 , the rat traverses the beam with no more than two footslips. Rats given 1.0 or $10.0 \mathrm{mg} / \mathrm{kg}$ of clozapine of had poorer overall recoveries than those given 0.1 or $0.5 \mathrm{mg} / \mathrm{kg}$ (ANOVA $\mathrm{F}_{4,51} ; p=0.014$, Fisher's LSD $p<0.02$, respectively). Clozapine had no effect on beam-walking scores in sham cortex-lesioned rats at any dose (data not shown). Reproduced from Goldstein and Bullman, $2002 .{ }^{39}$

importance of norepinephrine as a modulator of motor recovery after brain injury. The neurotoxin DSP-4 [N-(2chloroethyl)- $N$-ethyl-2-bromobenzylamine selectively destroys central noradrenergic neurons. Pretreatment with DSP-4 impaired motor recovery in rats after a subsequent injury to the cerebral cortex, but the norepinephrine depletion had no effect on locomotor activity in rats without a cortical lesion. ${ }^{40,41}$ The pontine nucleus locus ceruleus is the major source of noradrenergic projection fibers to the cerebral cortex. ${ }^{42-44}$ Cortical damage elicits changes in the norepinephrine content of the locus ceruleus. ${ }^{45} \mathrm{As}$ expected based on the DSP-4 experiments, bilateral locus ceruleus lesions prior to a unilateral sensorimotor cortex lesion results in poorer behavioral recoveries as compared to controls that had sham locus ceruleus lesions. ${ }^{46}$ Again, the locus ceruleus lesions had no effect on locomotion in rats that later had sham cortex lesions.

Although predominately ipsilateral, each locus ce- ruleus projects to both cerebral hemispheres ${ }^{47,48}$ and unilateral left or right locus ceruleus lesions similarly impair recovery after a subsequent right cortex lesion. ${ }^{46}$ Locus ceruleus neurons project to the cerebral cortex and subcortical structures via the dorsal noradrenergic bundle (DNB), which can also be lesioned permitting selective noradrenergic depletion of each hemisphere. ${ }^{49}$ Selective lesion of noradrenergic projection fibers to the cerebral cortex contralateral (but not ipsilateral) to a subsequent sensorimotor cortex lesion impairs the recovery of locomotor ability (FIG. 2). ${ }^{50}$ Moreover, the norepinephrine content in the contralateral but not ipsilateral cerebral cortex in rats with contralateral DNB-sham DNB lesions correlates with the rate of motor recovery. ${ }^{50}$ These results are not only consistent with the role of norepinephrine as a modulator of post-brain injury recovery, but suggest that the effect is mediated in the cerebral hemisphere contralateral to the site of cortical injury. 

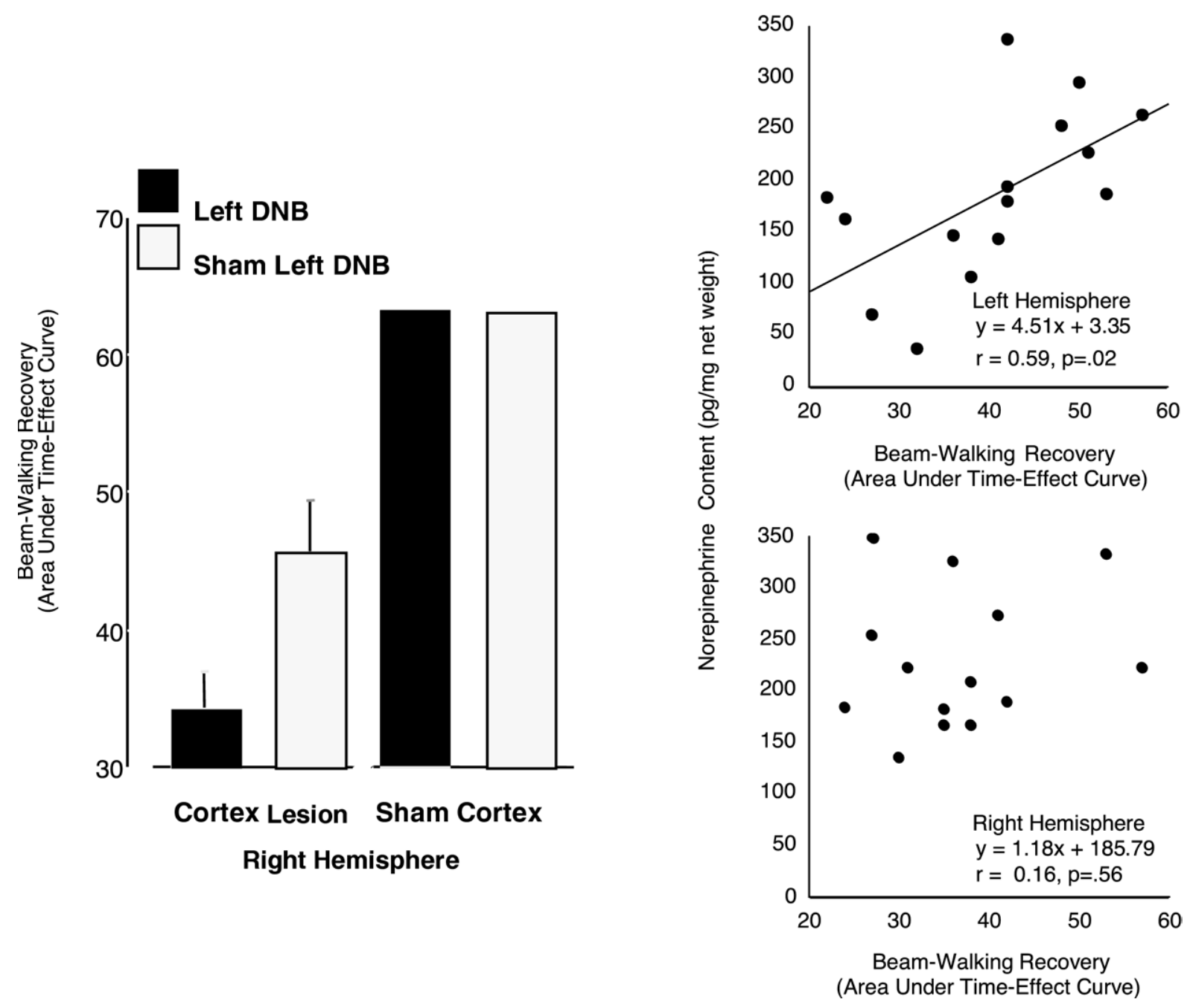

FIG. 2. Effects of prior left dorsal noradrenergic bundle (DNB) lesions on locomotor recovery after a subsequent right sensorimotor cortex lesion. Behavioral testing was performed with the same paradigm as described for FIG. 1. Each animal's recovery was calculated from the area under the curve formed by graphing score against time. The left panel shows recovery for animals with either a left DNB lesion (noradrenergically denervating the left cerebral hemisphere) or sham left DNB lesion prior to a right sensorimotor cortex lesion or sham right sensorimotor cortex lesion (Error bars are +/-SEM). Left DNB lesions had no effect on motor performance in rats with a subsequent sham sensorimotor cortex lesion. Cortex-lesioned rats with prior left DNB lesions had significantly impaired recoveries (areas under the time-effect curves) compared with cortex-lesioned rats with sham DNB lesions (ANOVA $F_{3,16}, p<0.001$; left DNB lesion-cortex lesion versus sham DNB lesion-cortex lesion, Fisher's LSD, $p<0.02)$. The right upper panel gives the correlation between recovery and norepinephrine content in the left cerebral hemisphere and the right lower panel shows the lack of correlation between recovery and norepinephrine content in the right cerebral hemisphere in these same animals. There was no effect of a right (ipsilateral) DNB lesion on recovery (data not shown). The results suggest that norepinephrine exerts its influence on locomotor recovery, at least in part, in the cerebral hemisphere contralateral to a sensorimotor cortex lesion. Modified from Goldstein and Bullman, $2002 .{ }^{50}$

Norepinephrine, experience, plasticity, and the contralateral homotypic cortex

After several weeks, there is use-dependent increased dendritic arborization in the homotypic cortex contralateral to a lesion of the forelimb sensorimotor cortex, followed by pruning and synaptogenesis, ${ }^{8,12,14,51-54}$ with increases in layer V synapse-toneuron ratios and dendritic arborizations that can be detected after approximately 30 days. ${ }^{12,14}$ The enhanced dendritic arborization is use-dependent (i.e., there are complex interrelationships among the effects of a brain lesion, behavioral experience, and neuro- anatomical changes). ${ }^{54,55}$ Neither a lesion nor asymmetrical limb-use alone accounts for the increases in contralateral layer $\mathrm{V}$ pyramidal neuron dendritic arborizations. ${ }^{55}$ These data are consistent with a relationship between recovery and norepinephrine content of the contralateral cerebral cortex.

\section{Interaction between pharmacological intervention} and experience or training in functional recovery after focal brain injury

As already noted, neurotransmitter-mediated effects on functional recovery after brain injury depend on the ani- 
mal's behavior. For example, with both amphetamine and haloperidol effects on motor recovery in rats are blocked if the animals are restrained rather than given motor practice after drug administration. ${ }^{25}$ A smaller effect of the drug is found in rats that are allowed to ambulate freely but are not given specific training, and more dramatic improvements of recovery occur if training is used in combination with the drug. ${ }^{10}$ The effect of amphetamine on motor recovery in cats with cortical injuries is also dependent on the animal's experience after lesioning. ${ }^{26}$ Similarly, amphetamine-facilitated recovery of stereoscopic vision in visually decorticated cats also depends on visual experience after the drug is given. $^{28}$

\section{Effect of norepinephrine on recovery: mechanism}

The cellular mechanisms that underlie learning provide a useful paradigm for considering the possible mechanism of norepinephrine-modulated recovery because the effect is experience dependent. Long-term potentiation (LTP) is the best-understood putative cellular mechanism of learning and memory. ${ }^{56,57}$ In the hippocampal formation, LTP is induced by a single, transient, high-frequency stimulation of excitatory neural inputs. Neurotransmitters such as catecholamines, ${ }^{58-61}$ GABA, ${ }^{62-64}$ and acetylcholine ${ }^{65,66}$ can affect LTP. Thus, it is possible that norepinephrine could initially affect LTP induction, which in turn could lead to the neuroanatomical changes discussed.

\section{OTHER NEUROTRANSMITTERS AND MOTOR RECOVERY}

Acetylcholine would be expected to facilitate the induction of LTP by suppressing voltage-activated potassium conductance. ${ }^{57}$ Activation of the muscarinic cholinergic receptor facilitates the induction of LTP in the rat dentate gyrus. ${ }^{67}$ Scopolamine, an anticholinergic, interferes with motor recovery after cortex infarction in rats. ${ }^{68}$ Giving acetylcholine has the opposite effect, facilitating recovery in animal brain injury models. ${ }^{69}$ It is also possible, however, that the putative effects of cholinergic drugs on recovery might be mediated by their indirect actions on noradrenergic neurons. ${ }^{70,71}$

GABA influences LTP and learning and memory. Stimulation of inhibitory GABAergic inputs to the hippocampal formation, ${ }^{63,72}$ as well as indirect GABA agonists such as benzodiazepines, suppress the induction of LTP. ${ }^{73}$ Intracortical infusion of the inhibitory neurotransmitter increases the hemiparesis produced by a small motor cortex lesion in rats. ${ }^{74}$ Diazepam, an indirect GABA agonist, impedes recovery from the sensory asymmetry caused by anterior-medial neocortex damage in the rat. ${ }^{75}$ Amphetamine administration influences the activity of GABAergic neurons, leading to lower extra- cellular GABA concentrations. ${ }^{76}$ This would be expected to enhance the induction of LTP.

More limited data are available concerning serotonin. Fluoxetine combined with training did not alter the degree or rate of recovery of function in rat, compared with nontreated animals. ${ }^{77}$

\section{SUMMARY}

There are complex interrelationships among the levels of certain central neurotransmitters, brain plasticity, behavioral experience, and recovery after brain injury. For locomotor recovery after injury to the sensorimotor cortex, extensive data indicate an important role for norepinephrine. Understanding the neurobiological processes underlying recovery, and how they might be manipulated, may lead to novel strategies to improve strokerelated gait impairments in humans.

\section{REFERENCES}

1. Rose FD, al-Khamees K, Davey MJ, Attree EA. Environmental enrichment following brain damage: an aid to recovery or compensation? Behav Brain Res 1993;5:93-100.

2. Kolb B, Forgie M, Gibb R, Gorny G, Rowntree S. Age, experience and the changing brain. Neurosci Biobehav Rev 1998;22:143-159.

3. Beaulieu C, Colonnier M. Richness of environment affects the numbers of contacts formed by boutons containing flat vesicles but does not alter the number of these boutons per neuron. J Comp Neurol 1988;274:347-356

4. Johansson BB. Functional outcome in rats transferred to an enriched environment 15 days after focal brain ischemia. Stroke 1996;27:324-326

5. Hamm RJ, Temple MD, O'Dell DM, Pike BR, Lyeth BG. Exposure to environmental complexity promotes recovery of cognitive function after traumatic brain injury. J Neurotrauma 1996;13: 41-47.

6. Schallert T, Woodlee MT, Fleming SM. Experimental focal ischemic injury: behavior-brain interactions and issues of animal handling and housing. ILAR J 2003;44:130-143.

7. Cotman CW, Berchtold NC. Exercise: a behavioral intervention to enhance brain health and plasticity. Trends Neurosci 2002;25:295301 .

8. Kleim JA, Jones TA, Schallert T. Motor enrichment and the induction of plasticity before or after brain injury. Neurochem Res 2003;28:1757-1769.

9. Goldstein LB, Davis JN. Beam-walking in rats: studies towards developing an animal model of functional recovery after brain injury. J Neurosci Methods 1990;31:101-107.

10. Goldstein LB, Davis JN. Post-lesion practice and amphetaminefacilitated recovery of beam-walking in the rat. Restor Neurol Neurosci 1990;1:311-314.

11. Nudo RJ, Wise BM, SiFuentes F, Milliken GW. Neural substrates for the effects of rehabilitative training on motor recovery after ischemic infarct. Science 1996;272:1791-1794.

12. Biernaskie J, Corbett D. Enriched rehabilitative training promotes improved forelimb motor function and enhanced dendritic growth after focal ischemic injury. J Neurosci 2001;21:5272-5280.

13. Biernaskie J, Chernenko G, Corbett D. Efficacy of rehabilitative experience declines with time after focal ischemic brain injury. J Neurosci 2004;24:1245-1254.

14. Jones TA, Chu CJ, Grande LA, Gregory AD. Motor skills training enhances lesion-induced structural plasticity in the motor cortex of adult rats. J Neurosci 1999;19:10153-10163.

15. Friel KM, Heddings AA, Nudo RJ. Effects of postlesion experience on behavioral recovery and neurophysiologic reorganization 
after cortical injury in primates. Neurorehabil Neural Repair 2000;14:187-198.

16. Humm JL, Kozlowski DA, Bland ST, James DC, Schallert T. Use-dependent exaggeration of brain injury: is glutamate involved? Exp Neurol 1999;157:349-358.

17. Bland ST, Schallert T, Strong R, Aronowski J, Grotta JC. Early exclusive use of the affected forelimb after moderate transient focal ischemia in rats: functional and anatomic outcome. Stroke 2000;31:1144-1151.

18. Kozlowski DA, James DC, Schallert T. Use-dependent exaggeration of neuronal injury after unilateral sensorimotor cortex lesions. J Neurosci 1996;16:4776-4786.

19. Humm JL, Kozlowski DA, James DC, Gotts JE, Schallert T. Use-dependent exacerbation of brain damage occurs during an early post-lesion vulnerable period. Brain Res 1998;783:286-292.

20. Risedal A, Zeng J, Johansson BB. Early training may exacerbate brain damage after focal brain ischemia in the rat. J Cereb Blood Flow Metab 1999;19:997-1003.

21. Leasure JL, Schallert T. Consequences of forced disuse of the impaired forelimb after unilateral cortical injury. Behav Brain Res 2004;150:83-91.

22. Jones TA, Bury SD, Adkins-Muir DL, Luke LM, Allred RP, Sakata JT. Importance of behavioral manipulations and measures in rat models of brain damage and brain repair. ILAR J 2003;44: $144-152$.

23. Kasamatsu T, Pettigrew JD, Ary M. Restoration of visual cortical plasticity by local microperfusion of norepinephrine. J Comp Neurol 1979;185:163-182.

24. Stroemer RP, Kent TA, Hulsebosch CE. Enhanced neocortical neural sprouting, synaptogenesis, and behavioral recovery with d-amphetamine therapy after neocortical infarction in rats. Stroke 1998;29:2381-2395.

25. Feeney DM, Gonzalez A, Law WA. Amphetamine, haloperidol, and experience interact to affect the rate of recovery after motor cortex injury. Science 1982;217:855-857.

26. Hovda DA, Feeney DM. Amphetamine with experience promotes recovery of locomotor function after unilateral frontal cortex injury in the cat. Brain Res 1984;298:358-361.

27. Sutton RL, Hovda DA, Feeney DM. Amphetamine accelerates recovery of locomotor function following bilateral frontal cortex ablation in cats. Behav Neurosci 1989;103:837-841.

28. Feeney DM, Hovda DA. Reinstatement of binocular depth perception by amphetamine and visual experience after visual cortex ablation. Brain Res 1985;342:352-356.

29. Hovda DA, Sutton RL, Feeney DM. Amphetamine-induced recovery of visual cliff performance after bilateral visual cortex ablation in cats: measurements of depth perception thresholds. Behav Neurosci 1989;103:574-584.

30. Boyeson MG, Feeney DM. Intraventricular norepinephrine facilitates motor recovery following sensorimotor cortex injury. Pharmacol Biochem Behav 1990;35:497-501.

31. Goldstein LB. Amphetamine-facilitated functional recovery after stroke. In: Ginsberg MD, Dietrich WD, editors. Cerebrovascular diseases. 16th Research (Princeton) Conference. New York: Raven Press; 1989. p. 303-308.

32. Goldstein LB, Poe HV, Davis JN. An animal model of recovery of function after stroke: facilitation of recovery by an $\alpha_{2}$-adrenergic receptor antagonist. Ann Neurol 1989;26:157.

33. Goldstein LB, Davis JN. Clonidine impairs recovery of beamwalking in rats. Brain Res 1990;508:305-309.

34. Sutton RL, Feeney DM. $\alpha$-Noradrenergic agonists and antagonists affect recovery and maintenance of beam-walking ability after sensorimotor cortex ablation in the rat. Restor Neurol Neurosci 1992;4:1-11.

35. Feeney DM, Westerberg VS. Norepinephrine and brain damage: $\alpha$-noradrenergic pharmacology alters functional recovery after cortical trauma. Can J Psychol 1990;44:233-252.

36. Hovda DA, Feeney DM, Salo AA, Boyeson MG. Phenoxybenzamine but not haloperidol reinstates all motor and sensory deficits in cats fully recovered from sensorimotor cortex ablations. Abstr Soc Neurosci 1983;9:1002.

37. Hovda DA, Feeney DM. Haloperidol blocks amphetamine induced recovery of binocular depth perception after bilateral visual cortex ablation in the cat. Proc West Pharmacol Soc 1985;28:209-211.

38. van Hasselt P. Effect of butyrophenones on motor function in rats after recovery from brain damage. Neuropharmacology 1973;12: 245-247.

39. Goldstein LB, Bullman S. Differential effects of haloperidol and clozapine on motor recovery after sensorimotor cortex injury in the rat. Neurorehabil Neural Repair 2002;16:321-325.

40. Goldstein LB, Coviello A, Miller GD, Davis JN. Norepinephrine depletion impairs motor recovery following sensorimotor cortex injury in the rat. Restor Neurol Neurosci 1991;3:41-47.

41. Boyeson MG, Callister TR, Cavazos JE. Biochemical and behavioral effects of a sensorimotor cortex injury in rats pretreated with the noradrenergic neurotoxin DSP-4. Behav Neurosci 1992;106: 964-973.

42. Ungerstedt U. Stereotaxic mapping of the monoamine pathways in rat brain. Acta Physiol Scand Suppl 1971;367:1-48.

43. Pickel VM, Segal M, Bloom F. A radioautographic study of the efferent pathways of the nucleus locus coeruleus. J Comp Neurol 1974;155:15-42.

44. Harik SI. Locus ceruleus lesion by local 6-hydroxydopamine infusion causes marked and specific destruction of noradrenergic neurons, long-term depletion of norepinephrine and the enzymes that synthesize it, and enhanced dopaminergic mechanisms in the ipsilateral cerebral cortex. J Neurosci 1984;4:699-707.

45. Gonzalez-Pina R, Bueno-Nava A, Montes S, et al. Pontine norepinephrine content after motor cortical ablation in rats. Proc West Pharmacol Soc 2005;48:73-76.

46. Goldstein LB. Effects of bilateral and unilateral locus coeruleus lesions on beam-walking recovery after subsequent unilateral sensorimotor cortex suction-ablation in the rat. Restor Neurol Neurosci 1997;11:55-63.

47. Kobayashi RM, Palkovitz M, Kopin IJ, Jacobowitz DM. Biochemical mapping of noradrenergic nerves arising from the rat locus coeruleus. Brain Res 1974;77:269-279.

48. Room P, Postema F, Korf J. Divergent axon collaterals of rat locus coeruleus neurons: demonstration by a fluorescent double labeling technique. Brain Res 1981;221:219-230.

49. Everitt BJ, Robbins TW, Gaskin M. The effects of lesions to ascending noradrenergic neurons on discrimination learning and performance in the rat. Neuroscience 1983;10:397-410.

50. Goldstein LB, Bullman S. Effects of dorsal noradrenergic bundle lesions on recovery after sensorimotor cortex injury. Pharmacol Biochem Behav 1997;58:1151-1157.

51. Schallert T, Leasure JL, Kolb B. Experience-associated structural events, subependymal cellular proliferative activity, and functional recovery after injury to the central nervous system. J Cereb Blood Flow Metab 2000;20:1513-1528.

52. Schallert T, Kozlowski DA, Humm JL, Cocke RR. Use-dependent structural events in recovery of function. Adv Neurol 1997;73: 229-238.

53. Jones TA, Schallert T. Overgrowth and pruning of dendrites in adult rats recovering from neocortical damage. Brain Res 1992; $581: 156-160$.

54. Schallert T, Jones TA. "Exuberant" neuronal growth after brain damage in adult rats: the essential role of behavioral experience. J Neural Transplant Plast 1993;4:193-198.

55. Jones TA, Schallert T. Use-dependent growth of pyramidal neurons after neocortical damage. J Neurosci 1994;14:2140-2152.

56. Bliss TVP, Dolphin AC. What is the mechanism of long-term potentiation in the hippocampus? Trends Neurosci 1982;5:289290.

57. Collingridge GL, Bliss TVP. NMDA receptors- their role in longterm potentiation. Trends Neurosci 1987;10:288-293.

58. Stanton PK, Sarvey JM. Blockade of norepinephrine-induced longlasting potentiation in the hippocampal dentate gyrus by an inhibitor of protein synthesis. Brain Res 1985;361:276-283.

59. Dahl D, Sarvey JM. Norepinephrine induces pathway-specific long-lasting potentiation and depression in the hippocampal dentate gyrus. Proc Natl Acad Sci U S A 1989;86:4776-4780.

60. Swanson LW, Teyler TJ, Thompson RF. Hippocampal long-term potentiation: mechanisms and implications for memory. Neurosci Res Program Bull 1982;20:601-769. 
61. Hopkins WF, Johnston D. Frequency-dependent noradrenergic modulation of long-term potentiation in the hippocampus. Science 1984;226:350-352.

62. Wigstrom H, Gustafsson B. Facilitation of hippocampal long-lasting potentiation by GABA antagonists. Acta Physiol Scand Suppl 1985;125:159-172.

63. Douglas RM, Goddard GV, Riives M. Inhibitory modulation of long-term potentiation: evidence for a postsynaptic locus of control. Brain Res 1982;240:259-272.

64. Olpe HR, Karlsson G. The effects of baclofen and two GABA B-receptor antagonists on long-term potentiation. Naunyn Schmiedebergs Arch Pharmacol 1990;342:194-197.

65. Ito T, Miura Y, Kadokawa T. Effects of physostigmine and scopolamine on long-term potentiation of hippocampal population spikes in rats. Can J Physiol Pharmacol 1988;66:1010-1016.

66. Williams S, Johnston D. Muscarinic depression of long-term potentiation in CA3 hippocampal neurons. Science 1988;242:84-87.

67. Burgard EC, Sarvey JM. Muscarinic receptor activation facilitates the induction of long-term potentiation (LTP) in the rat dentate gyrus. Neurosci Lett 1990;116:34-39.

68. De Ryck M, Duytschaever H, Janssen PAJ. Ionic channels, cholinergic mechanisms, and recovery of sensorimotor function after neocortical infarcts in rats. Stroke 1990;21:S58-S63.

69. Feeney DM, Sutton RL. Pharmacotherapy for recovery of function after brain injury. Crit Rev Neurobiol 1987;3:135-197.
70. Cheney DL, LeFevre HF, Racagni G. Choline acetyltransferase activity and mass fragmentographic measurement of acetylcholine in specific nuclei and tracts of rat brain. Neuropharmacology 1975; 14:801-809.

71. Kuhar MJ, Atweh SF, Bird SJ. Studies of cholinergic-monoaminergic interactions in rat brain. In: Butcher LL, editor. Cholinergicmonoaminergic interactions in the brain. New York: Academic Press; 1978. p. 211-227.

72. Douglas RM, McNaughton BL, Goddard GV. Commissural inhibition and facilitation of granule cell discharge in fascia dentata. J Comp Neurol 1983;219:285-294.

73. Riches IP, Brown MW. The effect of lorazepam upon hippocampal long-term potentiation Neurosci Lett 1986:S42. [Abstract].

74. Brailowsky S, Knight RT, Blood K. $\gamma$-Aminobutyric acid-induced potentiation of cortical hemiplegia. Brain Res 1986;362: 322-330.

75. Schallert T, Hernandez TD, Barth TM. Recovery of function after brain damage: severe and chronic disruption by diazepam. Brain Res 1986;379:104-111.

76. Bourdelais A, Kalivas PW. Amphetamine lowers extracellular GABA concentration in the ventral pallidum. Brain Res 1990;516: 132-136.

77. Windle V, Corbett D. Fluoxetine and recovery of motor function after focal ischemia in rats. Brain Res 2005;1044:25-32. 